\title{
Interaksi Simbolik Dalam Sales Promotion Menciptakan Brand Loyalty (Studi Kasus Pengguna Kartu Starbucks Di Jakarta)
}

\author{
Catherina Siena, Muhammad Adi Pribadi \\ catherina.915160121@stu.untar.ac.id,adipost@gmail.com,
}

Fakultas Ilmu Komunikasi Universitas Tarumanagara

\begin{abstract}
Marketing communication of a product is done to improve product quality and introduce products to consumers. Starbucks is a famous coffee shop in Indonesia. This research aims to determine the process of symbolic interaction in the formation of brand loyalty among Starbucks card users. This research uses symbolic interaction theory, brand loyalty and sales promotion. Symbolic interactions play a very important role in increasing consumer brand loyalty. This research uses a qualitative methodology. Data collection in this research was conducted by in-depth interviews and participant observation. The analytical method used in this research is a case study. The results showed that consumer loyalty to Starbucks, so they want to use Starbucks cards occurs because of the quality and promotion of Starbucks. And symbolic interaction is very influential in the process of brand loyalty formation such as promotions, rules and language used.
\end{abstract}

Keywords: brand loyalty, promotion, sales promotion, Starbucks card, symbolic interaction.

\begin{abstract}
Abstrak
Komunikasi Pemasaran terhadap sebuah produk dilakukan untuk meningkatkan kualitas produk dan memperkenalkan produk kepada konsumen. Starbucks adalah sebuah kedai kopi ternama di Indonesia. Penelitian ini bertujuan untuk mengetahui proses interaksi simbolik dalam pembentukkan brand loyalty diantara para pengguna kartu Starbucks. Penelitian ini menggunakan teori interaksi simbolik, brand loyalty dan sales promotion. Interaksi simbolik berperan sangat penting dalam meningkatkan brand loyalty konsumen. Penelitian ini menggunakan metodologi kualitatif. Pengumpulan data dalam penelitian ini dilakukan dengan wawancara mendalam dan observasi partisipan. Metode analisis yang dipakai dalam penelitian ini adalah studi kasus. Hasil penelitian menunjukkan bahwa keloyalitasan konsumen terhadap Starbucks, sehingga mereka mau menggunakan Starbucks card terjadi karena kualitas dan promosi di Starbucks. Dan interaksi simbolik sangat berpengaruh pada proses pembentukkan brand loyalty itu sendiri seperti promosi, peraturan dan bahasa yang digunakan.
\end{abstract}

Kata Kunci: brand loyalty, interaksi simbolik, promosi, sales promotion, Starbucks card

\section{Pendahuluan}

Brand Loyalty adalah kesetiaan pelanggan terhadap suatu produk. Kesetiaan ini berarti kemauan pelanggan untuk terus-menerus secara konsisten membeli produk tersebut dan tidak akan berpaling ke produk lain. Ada beberapa hal yang membuat pelanggan loyal dengan produk tersebut yaitu lebih percaya terhadap pilihannya, manfaat yang didapat lebih besar dari pada produk lain serta kualitas produk tersebut sudah tidak diragukan lagi (Kusuma, 2014).

Starbucks merupakan perusahaan yang sudah dikenal banyak orang. Tetapi di era sekarang, bisnis sudah berkembang dan beragam salah satunya adalah bisnis coffee 
shop, dimana-mana kita bisa menjumpai coffee shop. Sehingga hal ini mengurangi jumlah pelanggan di Starbucks. Oleh karena itu perusahaan Starbucks ingin membentuk sebuah brand loyalty.

Brand Loyalty sendiri merupakan sebuah ukuran kesetiaan pelanggan terhadap sebuah merek. Ukuran tersebut dapat memberikan gambaran tentang kesetiaan seorang pelanggan akan beralih ke merek lain atau tidak, terutama jika terdapat suatu perubahan, baik menyangkut harga atau atribut dan komponen lainnya terhadap merek tersebut.

Beberapa cara yang digunakan oleh perusahaan Starbucks untuk membangun brand loyalty itu sendiri beragam seperti buy 1 get 1, discount $50 \%$, tumblr day, dan salah satunya adalah member Starbucks card. Starbucks card sendiri menawarkan beberapa keuntungan seperti menukarkan satu reward (100 stars $)$ dengan minuman/makanan secara gratis. Cara ini dilakukan agar para pelanggan Starbucks tetap setia dengan brand ini dan tidak berpaling ke brand lain.

Berdasarkan latar belakang di atas, adapun perumusan masalah yang dihadapi sebagai berikut :

1. Bagaimana sales promotion berperan dalam terbentuknya brand loyalty diantara para pengguna kartu Starbucks?

Tujuan penelitian adalah sebagai berikut:

1. Untuk memahami proses interaksi simbolik dalam pembentukkan brand loyalty diantara para pengguna kartu Starbucks.

\section{Interaksi Simbolik}

Dalam buku Mead yang berjudul mind, self, dan society menjabarkan tiga konsep penting dari Teori Interaksi Simbolik. Berikut merupakan penjelasannya berdasarkan pada buku West \& Turner, 2008 :

\section{Pikiran (Mind)}

Pikiran merupakan kemampuan untuk menggunakan simbol dan simbol itu mempunyai sebuah makna sosial yang sama dan pikiran manusia harus dikembangkan dengan berinteraksi kepada orang lain. Di dalam pikiran terdapat 3 unsur penting yaitu significant symbol, thought dan role taking. Simbol-simbol yang bersifat verbal maupun nonverbal diatur untuk dapat mengekspresikan sebuah perasaan dan pemikiran agar dapat dimiliki bersama. (West dan Turner, 2008).

\section{Diri (Self)}

Diri (self) didefinisikan sebagai kemampuan untuk merefleksikan diri dari sudut pandang orang lain (West dan Turner, 2008). Terdapat 3 unsur penting dari diri yaitu cermin diri (looking-glass self), pantulan penilaian (reflected appraisals) dan efek pygmalion (Pygmalion effect). Teori ini mengemukakan bahwa kita mempunyai kemampuan untuk menjadi subjek dan objek bagi diri kita sendiri melalui bahasa. Di dalam diri terdapat $I$ dan $M e, I$ sebagai subjek dan $M e$ sebagai objek (West dan Turner, 2008).

Masyarakat (Society)

Ada dua bagian penting masyarakat yang mempengaruhi pikiran dan diri. Menurut Mead orang lain secara khusus (particular others) yaitu individu-individu dalam masyarakat yang signifikan bagi kita, biasanya anggota keluarga, kolega di 
tempat kerja dan teman ((West dan Turner, 2008). Sementara itu, menurut Joel M Charon dalam Pribadi, Suganda, Venus, dan Susanto (2018), orang lain secara umum (generalized other) yaitu masyarakat dapat terbentuk karena setiap individu yang berada di dalam masyarakat itu sepakat untuk melaksanakan aturan dan nilai yang telah disepakati bersama.

\section{Sales Promotion}

Sales promotion digolongkan sebagai penelitian konsumen atau perilaku konsumen. Salah satunya sering kali disebut untuk mempromosikan iklan. Teori ini memberikan pelajaran dalam upaya menjelaskan perilaku pembelian, hubungan antara berbagai jenis promosi penjualan, dan loyalitas merek. Promosi ada 2 jenis yaitu promosi moneter dan nonmoneter. Promosi moneter berupa seperti kupon dan diskon. Sementara promosi non moneter berupa sampel, display dan undian (Mendez, 2012).

Teori Sales Promotion mengamati lebih dekat perilaku konsumen. Teori ini menganalisis rangkaian variabel mendasar pada proses pemilihan merek yaitu: harga, harga referensi, kerugian dan keuntungan, kesetiaan, dan promosi. Perhatian khusus diberikan pada pengaruh promosi penjualan. Hasil yang disarankan oleh konsumen akan mempertimbangkan apakah ada promosi atau tidak, serta informasi harga, sebelum membuat keputusan pembelian.

Promosi dari pembelian sebelumnya secara berbeda dapat mempengaruhi pilihan merek, melalui umpan balik. Jika setelah membeli suatu merek dan ketika ditanya apakah anda menyukai merek ini atau hanya karena promosi dan jawabannya karena promosi makan umpan balik yang diberikan terhadap merek tersebut negative (Mendez, 2012).

Teori Sales Promotion juga mempunyai efek negatif terhadap penjualan. Beberapa dampak negatif dari promosi penjualan adalah peningkatan sensitivitas harga, penurunan loyalitas merek, dan erosi ekuitas merek. Tidak semua kegiatan promosi harga dipandang positif. Kepuasan atau ketidakpuasan promosi harga akan menjadi terkait dengan citra merek, jika konsumen menghubungkan penyebab kepuasan atau ketidakpuasan terhadap merek (Mendez, 2012).

Promosi bisa dilakukan di mana saja, bisa melalui iklan di televisi, melalui media sosial seperti yang kita ketahui Instagram, Facebook, Line bahkan jejaring internet lain seperti Email ataupun Youtube. Tidak hanya itu, promosi bisa dilakukan melalui sebuah banner, brosur atau billboard. Promosi dilakukan untuk menarik konsumen dalam membeli sebuah brand.

\section{Brand Loyalty}

Brand Loyalty adalah pengertian dari sejauh mana konsumen secara konsisten akan membeli merek yang sama dalam suatu produk. Dalam teori Brand Loyalty, perilaku dan promosi sangat berpengaruh. Konsumen menjadi loyal terhadap suatu merek yang memperkuat mereka. Loyalitas merek membuat konsumen membeli merek secara rutin dan menolak beralih ke merek lain. Oleh karena itu, sejauh itu jika konsumen loyal terhadap merek, maka ekuitas merek akan meningkat (Mendez, 2012).

\section{Metode Penelitian}

Pendekatan penelitian yang digunakan oleh penulis adalah penelitian kualitatif dan menggunakan metode studi kasus. Metode pengumpulan data yang dilakukan menggunakan wawancara mendalam, observasi partisipan, dokumentasi dan rekaman 
arsip. Subjek penelitian adalah pengguna kartu Starbucks, dan objek penelitian ini adalah Starbucks mampu membentuk sebuah brand loyalty terhadap konsumennya melalui Starbucks card. Teknik analisis data yang digunakan adalah reduksi data dan penyajian data, dan teknik keabsahan data yang digunakan adalah konfirmasi ulang. Dan menurut Engkus (2009) konfirmasi ulang adalah dengan mengirimkan hasil penelitian kepada narasumber-narasumber dan meminta mereka untuk mengoreksi dan memberikan masukan.

\section{Hasil Temuan dan Diskusi}

Peneliti berhasil melakukan wawancara mendalam dengan narasumber tentang apa yang membuat mereka loyal terhadap produk Starbucks, sehingga membuat mereka ingin berlangganan dengan cara menjadi member dari Starbucks, dan peneliti telah mendapatkan jawaban dari narasumber. Hasil temuan peneliti menunjukkan bahwa brand loyalty dari Starbucks terbentuk dari kualitas dan promosi.

\section{Kualitas}

Kualitas kopi di Starbucks sangat bagus, selain itu rasa dari berbagai kopi di Starbucks juga sangat enak, dan kopinya juga sangat original berbeda dengan coffee shop lainnya, hal ini dikarenakan Starbucks masih menggunakan mesin semi otomatis. Penggunaan mesin semi otomatis ini yang berkaitan dengan teori interaksi simbolik tentang generalized other, bahwa di setiap Starbucks masih menggunakan mesin tersebut dan untuk menjaga kualitas kopi agar rasanya tetap original.

Menurut para narasumber, Starbucks sangat konsisten dalam hal kualitas kopinya, karena Starbucks ngerolls kopinya sangat bagus dan tidak gosong, dan juga untuk Starbucks mereka mengambil kopi dari petani Sulawesi dan beansnya dari toraja sehingga rasa yang dihasilkan kopi Starbucks jauh lebih enak dibandingkan coffee shop lainnya.

"Hmm tergantung ya kalo misalnya kaya kopi aren yang lagi Instagramable yang murah banget, karena kopinya mereka itu tidak enak. Tapi kalo ngomongin Starbucks dia itu ngerolls memang tidak begitu gosong, dia Arabica, kadangkadang juga robusta dan aku suka. Mereka itu recent flavor gitu, eventhough kopinya mau dicampur kayak apalah tetap aja rasanya kopi sedangkan kalau kopikopi luaran yang murah banget ya mungkin mereka itu kopinya kopi sangrainya di rocenya kurang baik gitu sedangkan disini mereka branding juga kan kaya ngambil kopi dari petani Sulawesi, beansnya toraja kebanyakkan gitu-gitu sih" Mauren

Kondisi ini berkaitan dengan teori interaksi simbolik dalam generalized other dimana Starbucks konsisten mengambil kopi dari petani sulawesi dan beansnya dari toraja sehingga di semua Starbucks manapun, rasanya tetap akan sama dan kondisi ini menimbulkan terjadinya Brand Loyalty, dimana para narasumber merasa bahwa brand Starbucks tidak akan terganti oleh merk lain.

\section{Promosi}

Promosi yang dilakukan oleh Starbucks ini seperti ada promo buy 1 get 1 , lalu ada diskon $15 \%$ menggunakan gopay, dan juga pada tanggal 22 ada promo $50 \%$ dengan menggunakan tumbler Starbucks, lalu ada juga Starbucks Greener Day yaitu dengan menggunakan tumblr akan mendapatkan diskon 50\% tetapi hanya berlaku di tanggal tertentu saja, lalu ada Starbucks secret recipe yaitu beli 2 cuman seharga Rp. 
50.000, lalu ada juga beli 1 gratis 1 dengan menggunakan BCA dan juga promosi bisa didapatkan melalui kupon line Starbucks dengan cara ditukarkan kepada barista di Starbucks.

"Tiap sabtu minggu ada promo kredit card atau debit BCA buy 2 get 1, ada diskon 10\% kalau menggunakan Starbucks card, dari line juga pasti ada buy 1 get 1 atau tumbler day terus ada promo minuman apa gitu beli 2 cuman Rp 50.000 atau beli makanan dapat free tea" - Nadya-

Promosi tersebut berkaitan dengan teori sales promotion yang menjelaskan bahwa promosi tersebut tergolong di dalam promosi moneter yaitu promosi yang berupa kupon dan diskon, dan Starbucks memberikan promosi hampir semua menggunakan potongan harga.

Dalam sebuah promosi juga tidak melulu positif, ada beberapa hal negatif yang dirasakan oleh perusahaan Starbucks seperti ketika sedang tidak ada promosi, para konsumen tidak akan membeli ketika sedang tidak ada promosi, karena mungkin harganya yang cukup mahal dan hal ini juga disampaikan oleh seorang barista bernama Kevin.

"Ya karena Starbucks terlalu sering promosi ada yang 50\% atau tumblr, nah Starbucks karena terlalu sering mengeluarkan diskon-diskon jadi efek negatifnya adalah ketika sedang tidak ada diskon, orang nggak mau beli karena orang mau beli saat ada diskonnya aja seperti itu”-Kevin

Kondisi ini berkaitan dengan teori interaksi simbolik, ketika tidak ada promosi, maka jumlah konsumen yang datang tidak sebanyak ketika sedang ada promosi dan kondisi ini menunjukkan bahwa significant symbol tidak terjadi karena konsumen tidak akan datang ke Starbucks ketika sedang tidak ada promosi dikarenakan harganya yang mahal.

Tetapi hal ini berbeda kaitannya dengan para narasumber, mereka berpendapat bahwa ketika Starbucks sedang tidak ada promosi mereka tetap akan membelinya, hal ini dikarenakan mereka membeli Starbucks bukan karena promosi tetapi karena memang mereka menyukai produk Starbucks dan juga memang karena mereka ingin membeli saja.

"Engga sih sebenernya, saya membeli Starbucks karena kalau saya butuh kafein supaya ngga ngantuk dan yang kedua itu ya tadi nugas dan sambil kerja seperti ngerjain paper, skripsi atau project."-Mauren

Jadi ketika sedang tidak ada promosi pun bukanlah suatu masalah untuk para narasumber, mereka tetap akan membeli produk Starbucks tersebut, karena memang walaupun harga kopi di Starbucks cukup mahal tetapi kualitasnya memang tetap yang terbaik. Starbucks juga sangat konsisten dalam memberikan promosi, misalnya setiap hari sabtu ada promosi minuman dengan kartu $B C A$, dan untuk minggu depan ada lagi promosi tersebut di hari sabtunya.

Sebuah sales promotion tidak akan berhasil tanpa melalui saluran komunikasi yang tepat dan saluran komunikasi tersebut lah yang akan menentukan keberhasilan dari suatu kegiatan promosi. Di dalam sebuah promosi diperlukan banyak saluran komunikasi agar bisa berhasil, seperti contohnya dengan menggunakan sosial media, personal selling, email dan banner. 


\section{Media Sosial}

Perusahaan Starbucks sering sekali memberikan promosi-promosi menggunakan berbagai media, salah satunya adalah dengan menggunakan akun Line mereka dan Starbucks juga mempunyai Instagram sendiri dan sering mengunggah tentang promosi-promosinya.

"Biasanya dari line message itu mereka sering banget line saya, Instagram juga, dari banner mereka kalo lagi lewat Starbucks juga ada sama kadang teman juga suka ngasih tau ke saya juga sih gitu” -Denny

Kondisi ini terkait dengan teori interaksi simbolik dalam significant symbol, ketika Starbucks menawarkan promosinya melalui sosial media dan konsumen tertarik, maka significant symbol terjadi antara pembeli dengan Starbucks, dan kondisi ini termasuk dalam sales promotion, dimana perusahaan Starbucks akan selalu memberikan diskon berbeda setiap waktunya, hal ini digunakan untuk membuat konsumen loyal kepada Starbucks.

\section{Personal Selling}

Starbucks juga melakukan promosi dengan cara personal selling yaitu para baristanya sendiri yang menawarkan kepada konsumen tentang promosi-promosi apa yang sedang ada di hari ini atau minggu ini.

"Saya hampir setiap hari konsisten ke Starbucks di mall yang sama jadi kurang lebih kalau saya datang baristanya udah bilang kak hari ini ada promo ini loh gini-gini. Lagian even kalo saya bukan langganan tiap hari juga sepertinya barista juga memberikan promosinya soalnya saya pernah ke mall lain ke Starbucks juga mereka selalu sebutin sih hari ini ada promo apa saja" -Nadya

Kondisi ini berkaitan dengan teori interaksi simbolik dalam significant symbol, ketika barista menawarkan promosinya secara langsung dan konsumen tertarik, maka significant symbol terjadi antara pembeli dengan Starbucks. Dan kondisi ini juga sejalan dengan teori sales promotion, bahwa promosi tidak hanya melalui social media tetapi melalui personal selling antara barista dengan pembelinya.

\section{Email}

Starbucks juga seringkali memberikan informasi mengenai promosinya melalui email. Karena ketika pertama kali kita bikin Starbucks card pasti diminta emailnya, gunanya untuk memberitahukan kepada konsumen promosi apa saja yang ada di minggu ini.

"Sebenernya aku tipe orang yang cukup sering buka email ya, jadi kalo misalnya liat yaudah tapi kalo lagi enggak butuh kafein engga sih nggak pergi, atau dari temen sih biasanya yang kasih tau like I don't know beberapa orang kan ada yang promo hunter ya kayak tiba-tiba "ada promo nih kaya promo merdeka gitu." Dan liatnya kadang dari gojek gopay juga. Trus kalo gak "eh lagi ada promo nih, pink day gitu" dan salah satu tools mereka itu bikin campaign untuk menaikkan awareness atas kanker serviks ya kalo ga salah dan oleh karena itu semua minuman yang berwarna pink atau bernuansa like I don't know maybe female wannabe di diskon jadi buy 1 get 1 gitu" -Mauren

Kondisi ini berkaitan dengan teori interaksi simbolik dalam significant symbol dimana ketika perusahaan memberitahukan promosi-promosi melalui email dan 
konsumen menanggapinya berarti significant symbol terjadi dan kondisi ini juga berkaitan dengan sales promotion, dimana perusahaan memberitahukan promosipromosinya melalui email.

\section{Banner}

Selain dari social media, Starbucks juga melakukan promosinya melalui banner-banner yang terpasang di depan tokonya, karena untuk orang-orang tua sebagian dari mereka mungkin tidak bermain social media, atau mungkin bermain tetapi tidak begitu mengupdate tentang Starbucks, jadi digunakanlah banner-banner di depan Starbucks supaya konsumen yang sedang tidak melihat handphone, bisa langsung mengetahui promosinya melalui banner di depan Starbucks.

"Aku update banget sih karna aku selalu liatin instagramnya dan aku juga subscribe ke linenya jadi kemarin kan ada promo yang warnanya pink itu yang minumannya trus aku juga suka ngeliat kaya banner gitu di depannya Starbucks setiap kali ada promosi apa pasti ada tulisannya disana, terus kan sekarang Starbucks udah ada dimana-mana jadi setiap aku mau keluar ke kuliah itu aku ngelewatin Starbucks trus pergi ke mall juga ada Starbucks." - Natasya-

Kondisi ini berkaitan dengan teori interaksi simbolik dalam significant symbol dimana ketika perusahaan memberitahukan promosi-promosi melalui banner-banner di depan toko dan ketika konsumen melihatnya, mereka akan langsung membeli produk Starbucks di hari itu juga dan ini berarti bahwa significant symbol antara konsumen dengan promosi yang diberikan perusahaan Starbucks terjadi.

\section{Kesimpulan}

Sales promotion berperan sangat penting dalam pembentukkan brand loyalty, dimana Starbucks membuat sebuah loyalty card yang biasa disebut Starbucks Card dan memberikan promosi-promosi menarik setiap harinya dan juga memberikan reward kepada member Starbucks Card, sehingga membuat para narasumber merasa sangat puas sebagai konsumen.

Interaksi Simbolik yang terjadi berperan penting di dalam pembentukkan brand loyalty terhadap Starbucks, karena kualitas dari kopi Starbucks yang rasanya original dibanding kopi-kopi lainnya sehingga konsumen menyukai aroma khas Starbucks dan juga promosi yang diberikan Starbucks sangat sebanding dengan kualitasnya.

\section{Ucapan Terima Kasih}

Penulis mengucapkan terima kasih kepada pihak-pihak yang sudah membantu penulis dalam menyelesaikan penelitian ini, terutama kepada Tuhan yang Maha Esa, keluarga peneliti, dosen pembimbing dan juga teman-teman 1 bimbingan yang telah bersama-sama berjuang dalam menyelesaikan penelitian ini.

\section{Daftar Pustaka}

Christina, Nadya. (2019, November 03). Wawancara Pribadi

Ezra, Kevin. (2019, November 05). Wawancara Pribadi 
Kusuma, Yohanes Surya. (2014). Pengaruh Brand Experience terhadap Brand Loyalty melalui Brand Satisfaction dan Brand Trust Harley Davidson di Surabaya. Jurnal Manajemen Pemasaran Petra Vol.2, No.1, 1-11.

Kuswarno, Engkus. (2009). Metode Penelitian Komunikasi : Fenomenologi, Konsepsi, Pedoman dan Contoh Penelitiannya, Bandung: Widya Padjajaran

Mauren, Maya. (2019, November 01). Wawancara Pribadi

Mendez, Marife. (2012). Sales Promotions Effects On Brand Loyalty. Dissertation H. Wayne Huizenga School of Business and Entrepreneurship Nova Southeastern University.

Pribadi, Muhammad Adi, Suganda, Venus \& Susanto, Eko Harry (2018). Dinamika Perusahaan Periklanan Indonesia: Studi Kasus Komunikasi dan Budaya Organisasi Dwi Sapta IMC dan Fortune Indonesia. Disertasi Universitas Padjadjaran. Bandung: Universitas Padjajaran

Richard West, Lynn H.Turner. (2008). Pengantar Teori Komunikasi Analisis dan Aplikasi (Buku 1) (Edisi 3). Jakarta: Salemba Humanika

Suwatno. (2017). Komunikasi Pemasaran Kontekstual. PT. Remaja Rosdakarya Offset-Bandung.

Vernanda, Natasya. (2019, November 05). Wawancara Pribadi

Yin, Robert K. (2014). Studi Kasus Desain \& Metode. Jakarta: PT RajaGrafindo 